\title{
Analysis of degree of errors in handwritten medication prescriptions in Rafha, Saudi Arabia
}

\author{
Maria Abdul Ghafoor Raja, Manal Naif Aljuraisy, Nawaf Mohamed Alotaibi, \\ Muhammad Wahab Amjad* \\ Faculty of Pharmacy, Northern Border University, Rafha, Saudi Arabia
}

*For correspondence: Email: mwbamjad@yahoo.com; Tel: 00966-594838764

Sent for review: 22 February 2018

Revised accepted: 18 May 2019

\begin{abstract}
Purpose: To assess the prevalence of handwritten prescription errors in Rafha Central Hospital in Saudi Arabia, and to determine the most predominant type of prescription error.

Methods: A cross-sectional study was carried out on randomly selected samples of hand-written prescriptions in out-patient and in-patient pharmacies of Rafha Central Hospital over a five-month period (October 2016 to February 2017). A data collection sheet specially designed for this purpose was used to collect relevant information. The collected prescriptions were analyzed for the presence of prescription errors based on prescription parameters defined by the World Health Organization (WHO) and current guidelines published in British National Formulary (BNF). Descriptive statistics and Microsoft Office were used for processing and analyzing the data collected.

Results: Overall, 1019 prescription errors were identified. More than half of the total errors (610; $60 \%)$ were associated with missing patient's information. Moreover, the parameters related to drug and prescriber information were absent in 204 (20\%) and $5(0.4 \%)$ prescriptions, respectively. In addition, 200 (19\%) miscellaneous errors related to date, legible handwriting and directions for patients were identified.

Conclusion: This study discovered errors in hand-written prescriptions. A majority of the prescriptions did not adhere to accepted guidelines. The most common errors are absence of generic names of drugs, non-indication of duration of therapy or prescriber's contact address, and absence of patient's weight. Moreover, illegible handwriting was obvious in a substantial number of prescriptions.
\end{abstract}

Keywords: Prescription errors, Prescriber, Handwriting, Drug generic name

This is an Open Access article that uses a fund-ing model which does not charge readers or their institutions for access and distributed under the terms of the Creative Commons Attribution License (http://creativecommons.org/licenses/by/4.0) and the Budapest Open Access Initiative (http://www.budapestopenaccessinitiative.org/read), which permit unrestricted use, distribution, and reproduction in any medium, provided the original work is properly credited.

Tropical Journal of Pharmaceutical Research is indexed by Science Citation Index (SciSearch), Scopus, International Pharmaceutical Abstract, Chemical Abstracts, Embase, Index Copernicus, EBSCO, African Index Medicus, JournalSeek, Journal Citation Reports/Science Edition, Directory of Open Access Journals (DOAJ), African Journal Online, Bioline International, Open-J-Gate and Pharmacy Abstracts

\section{INTRODUCTION}

Prescription error has been defined as any avoidable event that might cause or result in harm or unsuitable medication to patient when the medicine is with the consumer, patient or healthcare professional [1]. Numerous types of clinical errors occur due to a number of factors which have been studied in depth in the literature [2]. The Institute of Medicine has characterized three kinds of medical errors: underuse (not prescribing when benefit is probable), overuse (prescribing when benefit is improbable) and misuse (mistake or error in prescription) [3,4]. 
Medical errors are the foremost causes of death, and they result in 44,000 annual casualties in United States of America (USA), with the likelihood of the annual casualty figure reaching $98,000[5,6]$. These errors cost the USA a staggering sum of $\$ 29$ billion annually [6]. Studies carried out in Australia [7], Canada [8] and New Zealand [9] have shown that the incidence of adverse events in these countries was similar to that in USA [10]. According to a separate study in the USA, medical errors are ranked third amongst the foremost causes of death. Studies have revealed that 106,000 deaths occurred every year from the adverse effects of medications, relative to the number of annual deaths from hospital infections $(80,000)$, needless surgeries (2000), hospital medication errors (7000), and miscellaneous errors $(20,000)$ $[11,12]$.

Research has shown that most medical errors are avoidable [13]. A Harvard University study has recommended the need to involve engineers specialized in healthcare so to improve the current medical errors [14]. Lately, the taxonomies of medical errors were studied and sorted according to developmental process, granularity and domain specificity [15]. It has been suggested that while designing safety assessment procedures of sociotechnical systems, human factor considerations should be included [16]. So far, the application of systems engineering and human factors in patient safety has been very scanty, and there is ambiguity regarding what it means to apply these principles [17]. The present study was conducted to assess the occurrence of prescription errors in paper form at Rafha Central Hospital in Saudi Arabia, and to determine the most prevalent type of these errors.

\section{EXPERIMENTAL}

\section{Study site and period of survey}

Rafha is a town in the north of Saudi Arabia, close to the border with Iraq. Rafha Central Hospital was selected for collecting data over a five-month period (October 2016 to February 2017).

\section{Study design}

A cross-sectional study was carried out on random samples of hand-written prescriptions in out-patient and in-patient pharmacies, without informing the physicians.

\section{Data collection}

Five hundred prescriptions were randomly collected for a period of five months. A data collection sheet specially designed for this purpose (attached in appendix) was used to collect relevant information. The collected prescriptions were analyzed for the presence of prescription errors, based on prescription parameters defined by World Health Organization [18] and current guidance published in British National Formulary (BNF) [19]. The data were evaluated using an analysis sheet containing all essential parameters defined by the WHO and BNF for writing prescriptions. These parameters included prescriber's information (name and signature), patient's information (name, age, gender, weight and address/telephone number); drug-related information (drug brand/generic/mixed name, strength, dose frequency, route of administration, duration and quantity of prescribed drugs), and miscellaneous information (directions for drug use by patients, legible handwriting and prescription date). Every prescription was screened to check if it met the criteria for good prescription writing by providing information on all the parameters stipulated in the analysis sheet.

\section{Statistical analysis}

Microsoft office and Descriptive Statistics were used for processing and analyzing the data. Statistical analysis was carried out with computational software Microsoft Excel 2010.

\section{RESULTS}

In this study, a total of 500 prescriptions were analyzed for prescriber's information, patient information, drug information, and miscellaneous information. Five prescriptions (1\%) were found to lack prescriber's signature (Table 1). However, the prescriber's names were indicated in all the prescriptions collected.

Table 1: Errors in prescriber information

\begin{tabular}{lcc}
\hline $\begin{array}{l}\text { WHO/BNF } \\
\text { parameter }\end{array}$ & Present & Absent \\
\hline Name & $500(100 \%)$ & $0(0 \%)$ \\
Signature & $495(99 \%)$ & $5(1 \%)$ \\
\hline
\end{tabular}

Table 2 shows results of analysis of patient's information. Prescriptions that lacked name, gender, and age were few, and comprised 3.8, 11.2 and $10.2 \%$, respectively. In contrast, a large number of prescriptions (96.8\%) did not contain information on patient's weight. Table 3 
shows the results of analysis of the prescriptions with respect to drug information. It was found that 177 (35.4\%), 273 (54.6\%) and 50 (10\%) prescriptions had generic, brand and mixed names, respectively. In 102 prescriptions (20.4 $\%)$, the drug names were not legible owing to unreadable handwriting. Analysis of strength, duration of therapy and route of administration revealed that these parameters were absent in $138(27.6 \%), 18$ (3.6\%), and 9 (1.8\%) prescriptions, respectively. Moreover, 18 prescriptions (3.6\%) lacked medication doses. Nevertheless, most of the prescriptions (479, $95.8 \%)$ stipulated drug frequency.

Table 2: Patients' information on prescription

\begin{tabular}{lll}
\hline $\begin{array}{l}\text { WHO/BNF } \\
\text { Parameter }\end{array}$ & \multicolumn{1}{c}{ Present } & Absent \\
\hline Name & $481(96.2 \%)$ & $19(3.8 \%)$ \\
Age & $449(89.9 \%)$ & $51(10.2 \%)$ \\
Weight & $16(3.2 \%)$ & $484(96.8 \%)$ \\
Gender & $444(88.8 \%)$ & $56(11.2 \%)$ \\
\hline
\end{tabular}

Table 3: Medication information on prescription

\begin{tabular}{lll}
\hline $\begin{array}{l}\text { WHO/BNF } \\
\text { parameter }\end{array}$ & Present & Absent \\
\hline Brand name & $177(35.4 \%)$ & $323(64.6 \%)$ \\
$\begin{array}{l}\text { Generic name } \\
\text { Mixed name }\end{array}$ & $273(54.6 \%)$ & $227(45.4 \%)$ \\
Unreadable & $50(10 \%)$ & $450(90 \%)$ \\
handwriting & $102(20.4 \%)$ & $398(79.6 \%)$ \\
Strength of drug & $326(65.2 \%)$ & $138(27.6 \%)$ \\
Dose of drug & $482(96.4 \%)$ & $18(3.6 \%)$ \\
Route of & $482(69.4 \%)$ & $18(3.6 \%)$ \\
$\begin{array}{l}\text { administration } \\
\text { Frequency of drug }\end{array}$ & $479(95.8 \%)$ & $21(4.2 \%)$ \\
Duration of drug & $491(98.2 \%)$ & $9(1.8 \%)$ \\
\hline
\end{tabular}

Table 4: Miscellaneous information on prescription

\begin{tabular}{lll}
\hline $\begin{array}{l}\text { WHO/BNF } \\
\text { parameter }\end{array}$ & Present & Absent \\
\hline Date of prescription & $494(98.8 \%)$ & $6(1.2 \%)$ \\
Legible handwriting & $419(83.8 \%)$ & $81(16.2 \%)$ \\
Direction for patient & $387(77.4 \%)$ & $113(22.6 \%)$ \\
\hline
\end{tabular}

A large number of deficiencies were observed with respect to directions for drug use to patients (Table 4). This was absent in 113 prescriptions (22.6\%). Date was present on 419 prescriptions (83.8\%), but 81 prescriptions (16.2\%) were not written in legible handwriting. Overall, a total of 1019 prescription errors were found (Figure 15). Approximately, more than half of these errors were related to non-indication of patient's information. On the other hand, prescriberrelated information and drug-related information were absent in 5 prescriptions (0.4\%) and 204 prescriptions (20\%), respectively. The number of miscellaneous-type errors (date, legible handwriting and directions for patients) was 200 $(19 \%)$.

\section{DISCUSSION}

In this study, 500 prescriptions were analyzed based on prescription writing criteria set by World Health Organization [18] and British National Formulary [19]. Prescriber information on prescriptions is essential because it aids the pharmacist to communicate with the physician/prescriber when explanations concerning the prescribed drug are required. The results of the study revealed that all the prescriptions analyzed contained complete prescriber's information, except only five prescriptions in which the prescribers' signatures were absent. These errors in prescriber information are smaller in number to that reported by Irshaid and coworkers who found that 16.7 and $18.1 \%$ prescriptions lacked prescriber name and prescriber signature, respectively [20]. Complete patient information on prescription is vital because it aids the pharmacist to check the prescription by asking the patient questions when necessary. Patient age and weight are used in the determination of dose, and they are applied by the pharmacist to check if the dose written is in order. In the current study, patient weight was absent in almost all prescriptions $(96.8 \%)$. This finding is consistent with the reports of Vaishali and et al. [21] and Irshaid et al [20] who found no information on patient's weight in the prescriptions they analyzed.

Furthermore, age is an important factor in the selection of correct medications because several drugs are not prescribed for some groups of patients such as pediatric and geriatric patients. The present study showed that patient's age was absent in only $10.2 \%$ of prescriptions. This finding is similar to that of Balbaid et al [22]. Some medicines are given only to one gender. Therefore, it is important to include the patient gender on prescriptions. The current findings revealed that $11.2 \%$ prescriptions did not indicate the gender of the patient. Similar results have been reported in earlier studies by Vaishali et al [21], and Balbaid et al [22] who discovered that 10 and $4.1 \%$ of prescriptions, respectively, lacked patient gender. However, the results of the present study differ from that of Irshaid et al [20] who reported that $48.7 \%$ prescriptions did not contain information on sex of the patient.

The results of the present study reveal that 35.4, 54.6 and $10 \%$ of prescriptions had brand, generic and mixed (i.e., both brand and generic) 
names of medications, respectively. This is at variance with the finding of Anuja et al [23] who revealed that only $7.4 \%$ prescriptions of pediatric outpatient department had generic names on them. In a study by Irshaid et al [20], brand name, generic name, and mixed names were present in 50.1, 15.1 and $28.3 \%$ of prescriptions, respectively.

Owing to rigorous promotional campaign by pharmaceutical enterprises, frequent prescription of drugs using brand names was observed in the present study. Nonetheless, medications prescribed with generic names are helpful in that they provide the pharmacist with the option of dispensing either the efficacious brands or the more economical brands. In this study, $20.4 \%$ of the prescriptions analyzed were illegible. It is important to indicate the strength of a medication in a prescription, especially when the medication is available in a variety of strengths.

The present study revealed that the strength of medication was absent in about $27.6 \%$ of the prescriptions analyzed, a finding similar to those of Vaishali et al [21], Irshaid et al [20] and Stubbs et al [24] who reporte that 26.8, 52.8 and $3.6 \%$ of prescriptions, respectively, did not indicate drug strength.

Drugs should be given to patients at the appropriate doses for safe and optimal effects. Hence, it is prescriber's responsibility to correctly write the drug dose on the prescription. The current study showed that only $3.6 \%$ of prescriptions failed to provide information on dose, or were not clear as to dose. This is at variance with some previous results [21,22].

Some medications are administered through multiple routes. In this case, it is vital to state the route of choice for the patient. The present study found that only $1.5 \%$ of prescriptions failed to indicate route of administration. This is in agreement with a previous report [24]. The duration and frequency of therapy are vital features of a prescription. It was discovered that a small percentage of prescriptions (1.8\%) did not indicate the duration of therapy. In earlier studies, Khaja et al [25] and Vaishali et al [21] found that 18.5 and $26.2 \%$ of prescriptions, respectively, did not stipulate the duration of therapy. In the current study, a small number of prescriptions lacked dosing frequency (4.2\%). Similar findings have been reported in earlier investigations [22,25].

Furthermore, the current study revealed that 1.2 $\%$ of prescriptions did not indicate date. This is consistent with the findings of Francois et al and
Balbaid et al [22] who reported that date was missing in 4.5 and $8.7 \%$ of prescriptions, respectively. However, $>50 \%$ of prescriptions lacked date in a study of prescriptions (of antibiotics) carried out in an Italian hospital. Illegible prescriptions may lead to fatal injuries and they constitute major causes of fatality. In the present study, $16.2 \%$ of prescriptions were not readable. Similar problems have been reported by other investigators [22]. It is vital to include the directions for patients such as followup advice or specific time for taking the medicine in a prescription. In the present study, $22.6 \%$ prescriptions did not contain these directions. In the study by Vaishali et al [21], $50 \%$ of prescriptions lacked patient instructions, while none contained follow-up advice.

Numerous proposals have been postulated by researchers around the world on how to improve writing of prescriptions. A study carried out in Holland in an intensive care unit (ICU) reported that the participation of pharmacists contributed to reduction of prescription errors. Other schools of thought recommended the use of e-prescribing system to decrease errors [24,25]. Indeed, studies have shown that e-prescribing systems significantly lowered prescription errors [22,23]. Thus, it is necessary to train prescribers on standard prescription rules. In addition, eprescription system should be introduced, and pharmacists should be involved in all steps of the medication process with respect to evaluation of prescriptions. These recommendations will significantly improve the quality of prescription writing and help reduce errors.

\section{Limitations of the study}

This study investigated the errors present in handwritten prescriptions in only one hospital (public sector). The study should have been widened to include other hospitals. In addition, a comparison between public sector hospitals and private hospitals with respect to prescription errors would provide a broader information.

\section{CONCLUSION}

This study exposes some prescription writing errors. A majority of the prescriptions did not adhere to appropriate guidelines. The most prevalent errors are absence of information on drug generic name, duration of therapy and patient's weight. Furthermore, a substantial percentage of prescriptions were written in illegible handwriting. Educational and training programs are needed for prescribers concerning appropriate writing of prescription. Execution of appropriate error reduction approaches such as 
appreciating the pharmacists' role at all stages of the medication process, use of software which caution on incidence of errors, introduction of computer-based prescription order entry systems, and error reporting may significantly improve prescription writing, while reducing the associated errors.

\section{DECLARATIONS}

\section{Acknowledgement}

The authors would like to thank the management of Rafha Central Hospital for their cooperation during this research.

\section{Conflict of interest}

No conflict of interest is associated with this work

\section{Contribution of authors}

We declare that this work was done by the authors named in this article and all liabilities pertaining to claims relating to the content of this article will be borne by the authors. Manal Naif Aljuraisy collected the data. Maria Abdul Ghafoor Raja supervised the study and analyzed the data. Muhammad Wahab Amjad and Nawaf Mohamed Alotaibi wrote the manuscript.

\section{Open Access}

This is an Open Access article that uses a funding model which does not charge readers or their institutions for access and distributed under the terms of the Creative Commons Attribution License (http://creativecommons.org/licenses/by/ 4.0) and the Budapest Open Access Initiative (http://www.budapestopenaccessinitiative.org/rea d), which permit unrestricted use, distribution, and reproduction in any medium, provided the original work is properly credited.

\section{REFERENCES}

1. United States pharmacopoeia. The standard. Rockville, Maryland, U.S. Pharmacopoeia, 1995.

2. Qureshi NA. Physicians' medication prescribing in primary care in Riyadh city, Saudi Arabia. Literature review, part 3: prescribing errors. East Mediterr Health J 2011; 17(2): 134-139.

3. Chassin MR, Galvin RW. Institute of Medicine National Roundtable on Health Care Quality. The urgent need to improve health care quality J Am Med Assoc 1998; 280: 1000-1005.
4. Neville RG, Robertson F, Livingstone S, Crombie IK. A classification of prescription errors. J R Coll Gen Pract 1989; 39: 110-112.

5. The National Academies, USA, http://www.nationalaca demies.org Accessed 2009.

6. Kohn L, Corrigan J, Donaldson M, Institute of Medicine. To Err Is Human: Building a Safer Health System, National Academy Press DC: Washington, 1999.

7. Runciman W, Moller J. latrogenic Injury in Australia: A report prepared by the Australian Patient Safety Foundation for the National Health Priorities and Quality Branch of the Department of Health and Aged Care of the Commonwealth Government of Australia, Adelaide. Australian Patient Safety Foundation, 2001.

8. Baker G, Norton P, Flintoft $V$, Blais R, Brown A, Cox J. The Canadian adverse events study: The incidence of adverse events among hospitals in Canada CMAJ 2004; 170: 1678-1686.

9. Ministry of Health, Adverse Events in New Zealand Public Hospitals: Principle Findings from National Survey, Wellington, New Zealand, 2001.

10. Institute of Medicine, Crossing the Quality Chasm: A New Health System for the 21st Century, National Academy Press, Washington, 2001.

11. Starfield B. Medical errors: $A$ leading cause of death. $J$ Am Med Assoc 2000; 284: 1267-1293.

12. Al-Harby N. Medical Errors Symposium [online], http://www.alriyadh.com/ 2007/02/18 /article 225849. html (Accessed 2009).

13. Meadows M. Strategies to reduce medical errors. FDA Consumer; 2003; 37: 20-27.

14. Wisconsin Engineer, USA, http://www.engr.wisc.edu/ wiscengr/april03/index.shtml (Accessed 2009).

15. Taib I, Mclntosh A, Caponecchia C, Baysari M. A review of medical error taxonomies: $A$ human factors perspective. Saf Sci 2011; 49: 607-615.

16. Cacciabue $P$, Vella $G$. Human factors engineering in healthcare systems: The problem of human error and accident management. Int J Med Inform 2010; 79: 1-17.

17. Rivera $A$, Karsh B. Human factors and systems engineering approach to patient safety for radiotherapy. Int J Radiat Oncol Biol Phys 2008; 71: 174-177.

18. De Vries TP, Henning RH, Hogerzeil HV, Fresle DA. Guide to good prescribing: A practical manual, Geneva world health organization 1995: 66-78 (WHO/DAP/94.11).

19. British National Formulary. BNF, 60th edition, British Medical Association and Royal Pharmaceutical Society of Great Britain, 2010.

20. Irshaid YM, Al Omrany M, Hamdi AA, Adjapon-Yamoah $K K$, Mahfouz $A A$. Compliance with good practice in prescription writing at outpatient clinics in Saudi Arabia. East Mediterr Health J 2005; 11(5-6): 922-928.

21. Vaishali DP, Deepak BP, Aarif SMM, Mishra A, Sikchi S, Kalakoti $P$. Prescription writing practices in a rural tertiary care hospital in Western Maharashtra, India. Australas Med J 2011; 4(1): 4-8. 
22. Balbaid OM, Al-Dawood KM. Assessment of physician's prescribing practices at Ministry of Health Hospitals in Jeddah City, Saudi Arabia. Saudi Med J 1998; 19: 28 35.

23. Pandey AA, Thakre SB, Bhatkule PR. Prescription Analysis of Pediatric Outpatient Practice in Nagpur City Indian J Community Med 2010; 35(1): 70-73.
24. Stubbs J, Haw C, Taylor David. Prescription errors in psychiatry- A multi-centre study. J Psychopharmacol 2006; 20(4): 553-561.

25. Khaja AKAJ, Sequeira RP, Al-Ansari TM, Damanhori $A H H$. Prescription writing skills of residents in a family practice residency programme in Bahrain. Postgrad Med J 2008; 84: 198-204. 